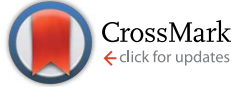

Cite this: RSC Adv., 2014, 4, 52156

Received 31st July 2014

Accepted 29th September 2014

DOI: $10.1039 / c 4 r a 07903 e$

www.rsc.org/advances

\section{Recent advances in the synthesis of inorganic nano/microstructures using microbial biotemplates and their applications}

\author{
R. Selvakumar, ${ }^{\text {a }}$ N. Seethalakshmi, ${ }^{a}$ P. Thavamani, ${ }^{b}$ Ravi Naidu ${ }^{b}$ \\ and Mallavarapu Megharaj*b
}

\begin{abstract}
Biotemplates from microbial origin have been a new source of inspiration for designing and fabricating intricate, high surface area structures that possess potent applications in nanotechnology. Microbial biotemplates are useful for synthesizing nano/micro structural materials based on a bottom up approach. Being from nature, microbial biotemplates with their extraordinarily molecular machinery have been reported to be considerably superior and cost effective for fabricating complex and heterogeneous structures when compared to the conventional and advanced lithographic techniques. The advantage of speedy growth and multiplication along with controlled shape, structure and size, make microorganisms a viable template for preparing nanomaterials of defined size and shape. In this review, we have consolidated the recent advances in the synthesis of nano/micro structures using biotemplates obtained from various types of microorganisms like bacteria, fungi, algae and virus, and have highlighted its possible applications. This review excludes biomolecules like DNA, protein and lipid based biotemplates extracted from various microorganisms.
\end{abstract}

\section{Introduction}

The synthesis of nanomaterials having controlled and defined geometries have been considered as a most challenging part of nanotechnology. The realization of such controlled geometries mainly depends on the method by which the nanomaterials have been synthesized. Synthesizing such nanomaterials with controlled geometries favor easy material assembly at the nanoscale and in turn increases the overall performance of the material. These assemblies ultimately can be used to form unique patterns essential for device fabrication. ${ }^{1}$ Various top down and bottom up approaches have been developed by several scientists to achieve such geometries that can be used in various applications. Recent techniques used for obtaining such unique geometries in nanomaterials using the top down approach are photolithography, electron, ion beam lithography, dip pen lithography, microcontact printing, electrochemical synthesis and nanoimprint lithography. The bottom up approach includes a patterned self-assembly process using topographically/chemically patterned surfaces and biotemplates. Among various advantages and disadvantages of the top down and bottom approaches, biotemplating always

${ }^{a}$ Nanobiotechnology Laboratory, PSG Institute of Advanced Studies, Coimbatore 641004, India.E-mail: selvabiotech@gmail.com

${ }^{b}$ Centre for Environmental Risk Assessment and Remediation (CERAR), University of South Australia, Mawson Lakes, Adelaide 5095, Australia. E-mail: megharaj. mallavarapu@unisa.edu.au remains a cost effective alternative for the synthesis of size/ shape controlled patterned nanostructures. (For further details on the advantages and disadvantages of top down and bottom up approaches for size and shape dependent nanomaterial formation, please read the review written by Sotiropoulou et al. $)^{1}$. Template assisted synthesis is a low cost, easy and versatile method to fabricate nanomaterials with defined structures. This method uses templates having micro/nano sized known patterns/pores or shapes of metal/biological/ polymeric or chemical origin. A material of choice can be deposited onto such templates and grown to form respective nanomaterials having the shape of the template. Once the material is grown over the template, the templates are removed either partially or completely by suitable methods to produce free standing nanostructures. ${ }^{2}$ Integrating biosystems into the nanotechnology has been taken up as an important and novel task by many researchers in recent years. Being from nature, the molecular machinery of a biosystem always outperforms extraordinarily when compared to all the above mentioned man-made manufacturing technologies. ${ }^{3}$ The natural molecular self-assembly process and the resultant precise and unique biological structures have inspired material scientists to look at them as a possible biotemplate for nanotechnology. The biotemplates used for biomorphic mineralization processes impart a nanoscale constraint for the synthesis of nanoscale materials resembling the biotemplate. Biotemplates also act as stabilizers and make them monodisperse in nature. ${ }^{4}$ The nanostructures formed using these types of biotemplate from living system 
have many advantages. These biotemplates are natural, ecofriendly, inexpensive, having metal ion binding capacity, stability and high production yield. They can be used to synthesize nanomaterials at room temperature using soft chemical processes, which are mostly ecofriendly in nature. Biological systems have been reported to exhibit multiple levels of hierarchical structures from microscopic to macroscopic length scale. ${ }^{5}$ Despite the presence of micro and macroscale structures in biological systems, their building blocks are mostly in nanoscale. The examples of such naturally available nanostructures include nanostructure in bone formation, ${ }^{6}$ nanostructures in lotus leaf, 7 nanostructures reported in butterfly wings and nanostructures in various living organism. ${ }^{8-10}$ Microorganisms and their nano and microstructures are always the most preferable biotemplate because of their low generation time, easy growth conditions, possibility of mass multiplication and scalability and its inherent resistant properties towards various environmental conditions. The microbial cell wall functional groups like carboxyl, phosphate and amide groups favor an atmosphere for metal binding and nucleation, which in turn leads to the formation of nanoparticles/structures on its surface. ${ }^{11}$ The exopolysaccharides produced by these microbes especially bacteria impart negative charge through carboxyl and phosphate groups, which also allow the nucleation of positive charged metals like silver and leads to the formation of nanostructures in solution. ${ }^{12}$

Considering these facts and advantages of biotemplating, several researchers have focused onto microbes with unique structural and functional properties as a possible biotemplate for the synthesis of nanostructures of different size, shape and morphology. In this review, we have consolidated the recent updates on the use of microorganism as biotemplate for the nanostructure formation. We have excluded extracellular and intracellular synthesis of nanoparticles by microorganisms because several reviews are available on it. Bacterial, viral, fungal and algae including diatoms based biotemplates have been taken into consideration. We have also highlighted the application of nanostructures derived through these microorganism based biotemplates.

\section{Microorganism based biotemplate}

\subsection{Bacteria based biotemplates}

2.1.1 Whole cell template. Various living microorganisms and their features are closely related to the recent nanostructures developed using chemical and physical methods. Hence these living microbes and their special structures can be used as biotemplate. Bacterial surface structures and morphology is one such feature looked into as a biotemplate. Different strains of bacteria such as B. subtilis, E. coli, S. thermophilus, $S$. typhimurium have been used as templates for the micro/nanostructure formation. Some of the bacteria possess self-assembled nanostructures on its cell wall which is made up of surface layer proteins (S layer).$^{13}$ These S-layer proteins have multiple functions like maintenance of cell shape and structure, template for fine grain mineralization, pathogenicity and cell adhesion, surface recognisation, as a protective coat and for attachment to surface which makes them survive in adverse environmental conditions. ${ }^{\mathbf{1 4 , 1 5}}$ These protein nanostructures are either found embedded into the cell wall surface or attached to the cell wall superficially through secondary cell wall polymers. ${ }^{16}$ The assembly of S-layer protein can be of different symmetries like $P 1, P 2, P 3, P 4$ and $P 6$ and differs from one organism to the other. Such symmetries give different structural arrangement and shape to cell wall surface which can inturn be used as biotemplate. The $P 1$ and $P 2$ symmetry give oblique template structure where as $P 3$ and $P 6$ give hexagonal structure to the cell wall surface. $P 4$ gives square shaped structure (Fig. 1). These S-layers can be reassembled into defined symmetries even onto various matrices like mica, silicon, lipid interfaces,

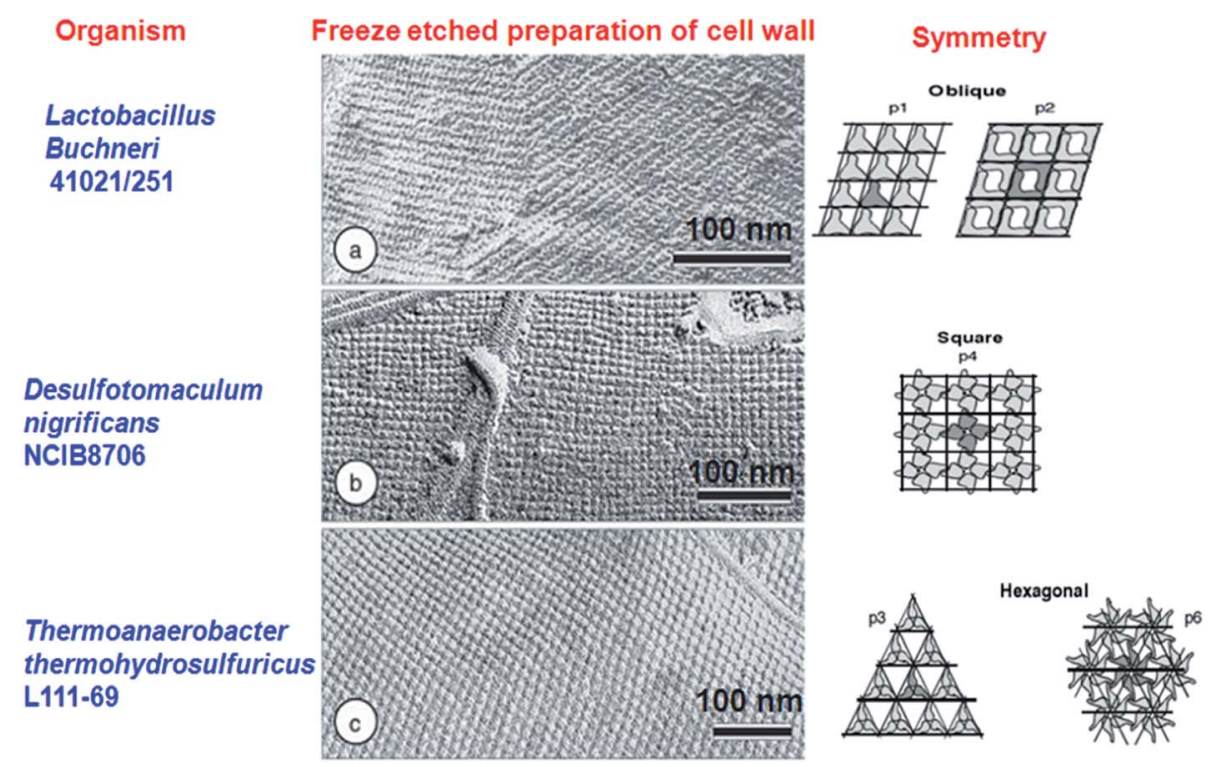

Fig. 1 Bacterial cell wall with different types of S-layer symmetries and structures. Adopted from ref. 16 with permission. 
liposomes, nanocapsules, polyelectrolyte layers and even on solution there by acting as a suitable biotemplate for further synthesis of different nanostructure having precise shape and size. ${ }^{17}$ Mark et al. ${ }^{18,19}$ used 2D microbial S-layer protein biotemplate for preparing dentrimer-encapsulated nanoparticle arrays and metallic and semiconductor nanoparticle arrays. Mark et al. $^{20}$ tried using S-layer protein based biotemplated assembly of colloidal gold etch mask for the fabrication of silicon nanopillar arrays. These nanopillars were of $60-90 \mathrm{~nm}$ tall, $8-13 \mathrm{~nm}$ wide at the tip, 15-20 $\mathrm{nm}$ wide at half height and 20-30 nm at base (Fig. 2). Silica enhanced S-layer protein cages were prepared by Schuster et al. ${ }^{21}$ using liposomal assembly. S-layers were reassembled onto liposomes and subjected to silicification. After silicification, the lipid components were dissolved using suitable detergent. The organism without S-layer and with S-layer can as such be used as biotemplate to synthesis defined nano/microstructures. Bacteria use their efflux system/oxidation/reduction mechanisms/cell wall functional groups to detoxify the metal contaminants that they encounter in the surrounding media and escapes from the environmental stress. Bacteria like Shewanella sp. strain HN-41 have been reported to produce arsenic-sulphide nanotubes of 20-100 $\mathrm{nm}$ in diameter by $30 \mu \mathrm{m}$ in length via reduction of As(v) and $\mathrm{S}_{2} \mathrm{O}_{3}{ }^{2-}$ using dissimilatory metal reducing process. These nanotubes behaved as metal and semiconductor nanomaterial with electrical and photocatalytic property, which can find applications in nano and optoelectronics. ${ }^{22}$ This potential of bacteria to accumulate metals/minerals intra- or extracellularly has made them an ideal candidate for biotemplate leading to a nanostructure formation., ${ }^{\mathbf{4} 23}$ Nickel nanostructure was synthesized using Bacillus subtilis as a biotemplate by exploiting the redox reactions of their surface amino acids. Microscopic studies revealed the formation of nanostructures according to the morphology of the bacteria used. ${ }^{24} \mathrm{ZnO}, \mathrm{ZnS}$ and $\mathrm{TiO}_{2}$ nanostructures were prepared using Streptococcus thermophilus and Lactobacillus bulgaricus as biotemplate (Fig. 3). ZnO hollow spheres were prepared using Streptococcus thermophilus as biotemplate through a simple hydrothermal process followed by calcinations at $600{ }^{\circ} \mathrm{C}$ (Fig. 3, method 1). ${ }^{25} \mathrm{ZnS}$ nanostructures were formed using these biotemplate through sonochemical and ultrasound process. ZnS nanoparticles were subjected to sonication in the presence of bacterial template to form $\mathrm{ZnS}$ nanoclusters coated bacterial structure. Followed by formation of $\mathrm{ZnS}$ nanoclusters the cellular materials were removed by high intensity ultrasound process leaving the hollow $\mathrm{ZnS}$ nanostructure behind (Fig. 3, method 2). ${ }^{26}$ Yang et al. ${ }^{27}$ prepared hollow porous silver microspheres using Streptococcus thermophilus as a bacterial template using same approach of sonication. They found that these silver microspheres were Raman active when tagged with Raman probe like 2-mercaptopyridine using surface enhanced Raman spectroscopy (SERS) study. The silver microspheres were also porous in nature there by exhibiting higher surface area for interaction. Zhou et al. ${ }^{28}$ prepared $\mathrm{TiO}_{2}$ micro/nanostructures using these bacterial templates through a surface sol-gel process. The hollow sphere and tube structures of $\mathrm{TiO}_{2}$ nanostructures were formed through a series of hydrolysis processes and calcinations (at $700{ }^{\circ} \mathrm{C}$ ) and tested for photocatalytic activity. These structures were found to show high photocatalytic activity under UV-visible radiation (Fig. 3, method 3). Recently, Zhang et al. ${ }^{29}$ have prepared $\mathrm{Co}_{3} \mathrm{O}_{4}$ decorated $\mathrm{ZnO}$ hollow spheres with a porous shell at a low temperature using Microzyme cells as a biotemplate and have tested it for sensing gases like $\mathrm{CO}, \mathrm{H}_{2}, \mathrm{H}_{2} \mathrm{~S}$, and vapors of ethanol and acetone. These $\mathrm{Co}_{3} \mathrm{O}_{4}$-decorated $\mathrm{ZnO}$ hollow spheres were effective in sensing acetone followed by ethanol; whereas, the same structures were ineffective in sensing $\mathrm{CO}, \mathrm{H}_{2}$ and $\mathrm{H}_{2} \mathrm{~S}$ at $50 \mathrm{ppm}$ of initial concentration. Bacteria/ZnO core-shell spheres have been prepared by a hydrothermal method. The formation of such structures mainly depends on the $\mathrm{pH}$ of the medium. At acidic pH, metal ions bind to the carboxyl and phosphate groups of the biotemplate. The metal ions form a complex with the amine group at $\mathrm{pH}$ higher than 8 and leads to core-shell like structure. ${ }^{26}$ Hollow zirconia particles were synthesized using E.coli cells as a biotemplate. It has been observed that the presence of water in templates results in the hydrolysis of zirconium butoxide leading to the formation of zirconia hollow particles. ${ }^{30}$ Yang et al. ${ }^{31}$ developed hierarchically branched Au-nanowire/E.coli nanocomposites using CTAB directed bacterial template (E.coli). These Au-nanowires showed increased adsorption at near IR region (1900 nm). Kaehr and Brinker $^{32}$ reported that the segregation of a catalytic region on a biotemplate is possible by exploiting the polar segregation process of dividing E.coli cells. They also suggested that the formation of more complex materials and architectures are
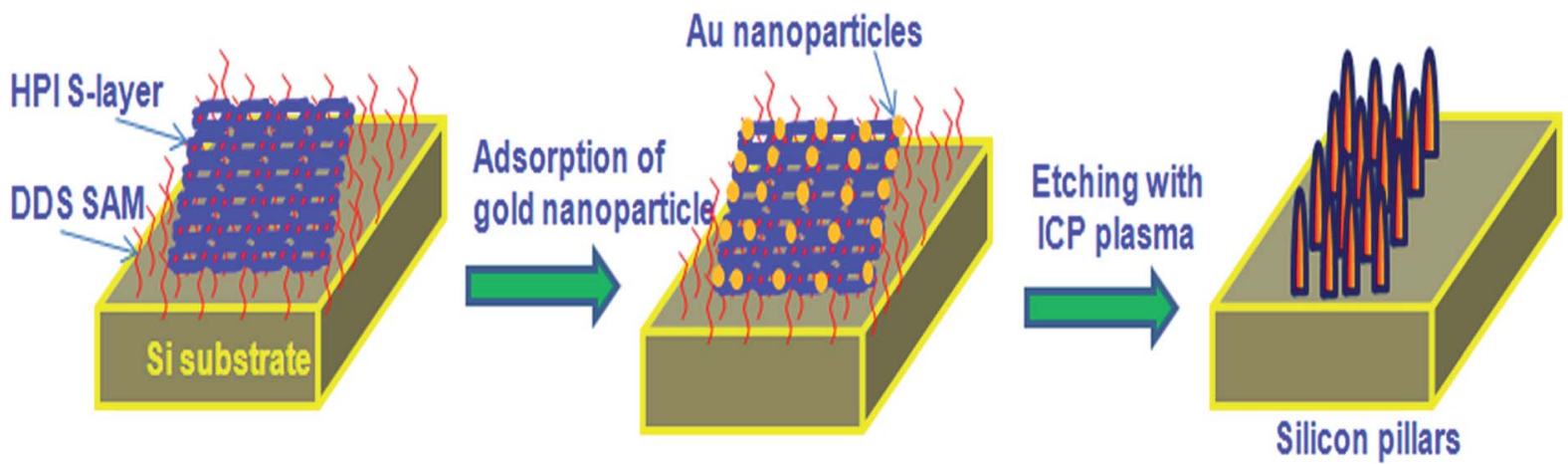

Fig. 2 Bionanofabrication of vertically aligned silicon based nanostructures using bacterial S-layers. Modified from ref. 20 with permission. 


\section{Method 1}

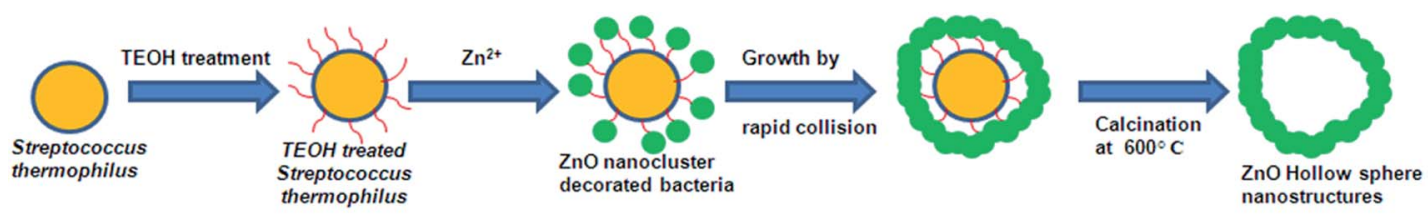

\section{Method 2}

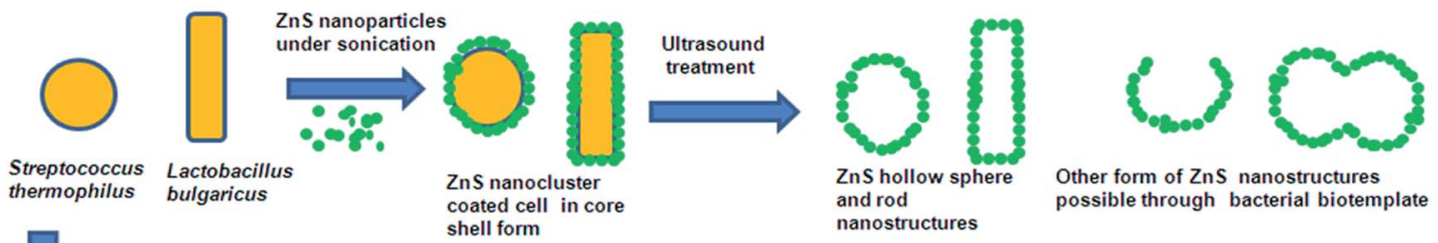

\section{Method 3}
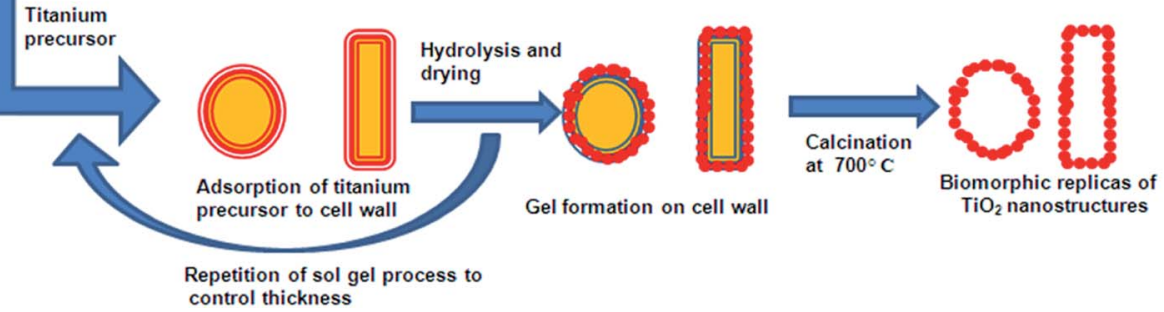

Fig. 3 Synthesis of various forms of $\mathrm{ZnO}, \mathrm{ZnS}$ and $\mathrm{TiO}_{2}$ nano/microstructure using bacterial morphology. ${ }^{25,26,28}$

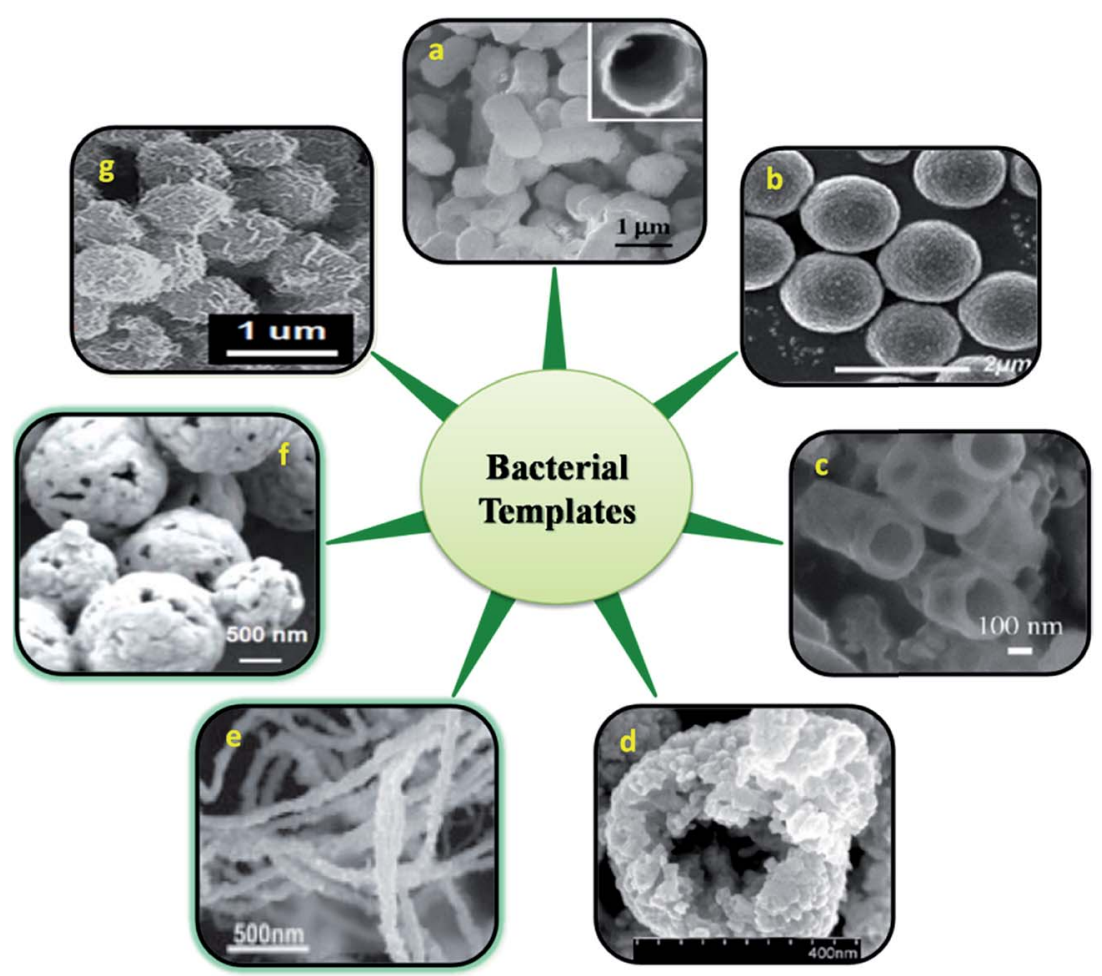

Fig. 4 Various nanostructures derived using entire cell of bacteria. FESEM images of E. coli templated hollow silica microparticles (a) (insert: cross sectional view of calcined particle), ${ }^{84} \mathrm{~B}$. sthermophilus/ZnO core-shell spheres (b), ${ }^{25} \mathrm{SEM}$ images of crushed calcined zirconia particles using E.coli template (c), ${ }^{30} \mathrm{CO}_{3} \mathrm{O}_{4}$-decorated $\mathrm{ZnO}$ hollow spheres (d), ${ }^{29} \mathrm{Au}$ nanostructures synthesized by the reduction of aqueous $\mathrm{HAuCl}$ (e), ${ }^{31}$ SEM image of $\mathrm{H}_{2} \mathrm{O}_{2}$ etched $\mathrm{Ag}$ microspheres at a higher magnification using $\mathrm{S}$. thermophilus template (f), ${ }^{27} \mathrm{FE}-\mathrm{SEM}$ image of uniform, bacteriasupported, hierarchical $\mathrm{CO}_{3} \mathrm{O}_{4}$ superstructures produced without changing the spherical shape of the original micrococcus template (g) ${ }^{85}$ [all images were obtained with permission]. 
possible by chemical, genetical and confinement induced modification in bacterial morphology and bacterial surface properties. Various nanostructures obtained using whole bacterial cell as a biotemplate has been consolidated in Fig. 4 .

2.1.2 Bacterial flagella. Other than the entire cell, bacterial structures like flagella and pili have been used as a biotemplate for the synthesis of nanostructures. These flagella and pili are used for mobilization and communication between one bacterium to the other. Natural and genetically engineered flagella have been studied as templates/scaffolds for the formation of metal nanostructures. ${ }^{33,34}$ Hesse et $a l .{ }^{34}$ used a mineralization process for the formation of nanotubes from bacterial flagella. They depolymerised the flagella into flagellin monomers and repolymerized it using $\mathrm{Na}_{2} \mathrm{SO}_{4}$ to form flagellin seeds. These seeds were further used to develop lengthy flagella. The repolymerised lengthy flagella were deposited with titanium by a ceramic thin film deposition technique and further mineralization at $50{ }^{\circ} \mathrm{C}$ to obtain flagella coated with $\mathrm{TiO}_{2}$ nanoparticles of anatase phase having a particle size of 5-10 $\mathrm{nm}$. On annealing these flagella coated with $\mathrm{TiO}_{2}$ nanoparticles at $200{ }^{\circ} \mathrm{C}$, they achieved nanotubes sized from $200-300 \mathrm{~nm}$ in diameter. Our group used similar approach to develop one dimensional silver nanoparticle coated nano/micro structure using Salmonella typhimurium flagella. ${ }^{35}$ In this work, we have demonstrated two different approaches to prepare flagella based silver nanoparticle coated bionanomaterial (Fig. 5) having increased conductivity. We have also proved that the deposition of such bionanomaterials onto a graphite electrode can enhance the conductivity of the electrode surface that can be used in microbial fuel cells. ${ }^{36}$ Similar nanoparticle impregnated flagella was prepared by Deplanche et al. ${ }^{33}$ They immobilized stable gold and palladium nanoparticles onto normal and genetically engineered flagella isolated from Desulfovibrio desulfuricans to form nano-microstructures, which can be useful for catalyst formulations. Mudalige et $a l .{ }^{37}$ synthesized various nanoparticle arrays using engineered bacterial flagellar FliC proteins obtained from mesophilic bacteria. The FliC protein was further modified at peptide loops, such as histidine and cysteine loops, and various nanoparticles like $\mathrm{Au}, \mathrm{Ag}$, and $\mathrm{Cd}$ were allowed to bind to the histidine loops. Such binding resulted in an ordered array of nanoparticles on flagella nanotubes. They also prepared other organic and inorganic nanoparticle arrays and nanotubes made of hydroxyapatite, silica and titania using a similar approach. ${ }^{38}$ Ovalbumin coated flagellin nanoparticle were prepared from Salmonella enteritidis derived flagellin and studied for its immune adjuvant capacity for the development of an oral vaccine. ${ }^{39}$ They reported that the vaccine conjugated with flagellin in the form of a nanoparticle along with ovalbumin were found to exhibit strong, long lasting systemic and mucosal immune responses than the respective non-conjugated vectors. Wang et $a l^{40}$ synthesized periodic nanohole arrays along with silica fibers using high temperature calcinations of silica nanotubes synthesized using flagella obtained from Salmonella sp. They also demonstrated the application of these double-layered silica-flagella nanotubes for selective CdTe quantum dot uptake into the innerchannels or selective $\mathrm{Au}$ nanoparticle coating on the outer wall of the nanotubes by the difference in chemistry between inner flagellum core protein and outer silica wall of the nanotubes. Jo et $a{ }^{41}$ prepared silica nanotubes using bacterial flagella as template and coated them with various types of nanoparticles made up of gold, palladium and iron oxide using reductive metallization or oxidative hydrolysis. Similar to Jo et al. ${ }^{\mathbf{4 1}} \mathrm{Li}$ et $a .^{\mathbf{4 2}}$ prepared morphologically controlled silica nanotubes using bacterial flagella as a biotemplate. They manipulated the morphology by changing the $\mathrm{pH}$ and using a peptide display to prepare silica nanotubes. They were also successful in preparing sol-gel mediated hollow double layered core-shell titania/silica nanotubes under ambient conditions using

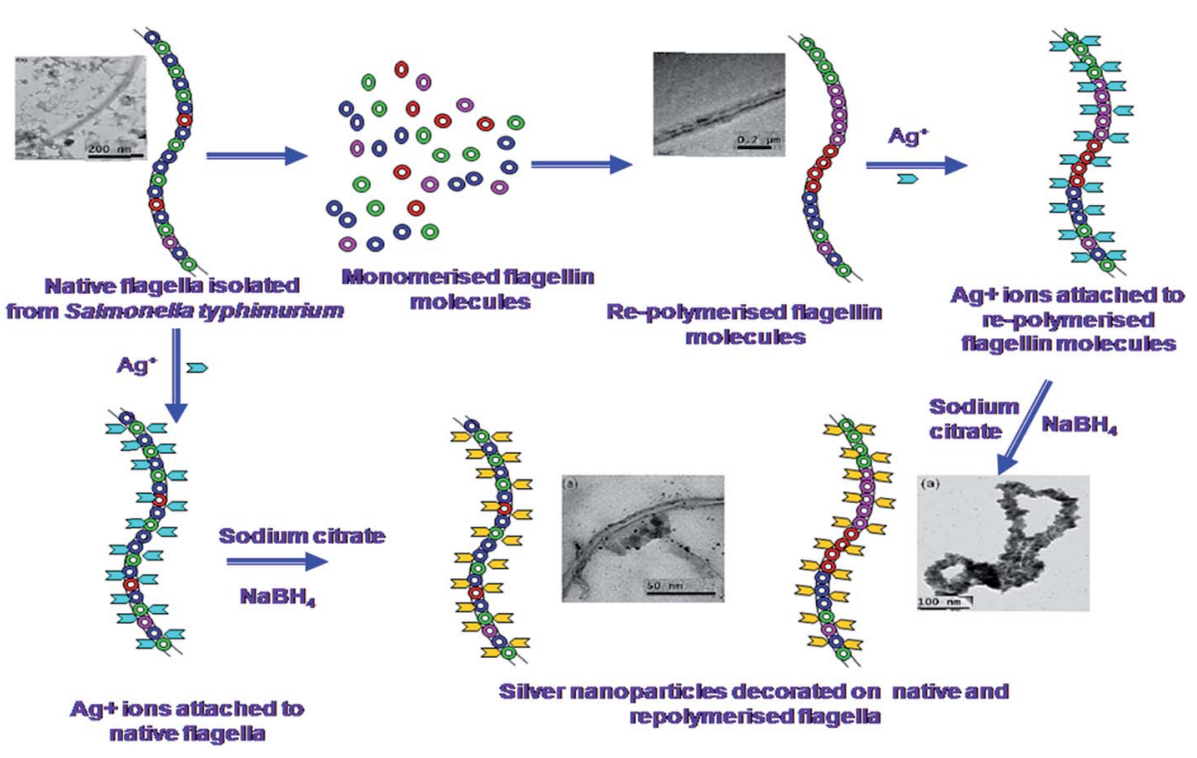

Fig. 5 Possible mechanism for silver nanoparticle impregnation onto bacterial flagella ${ }^{35}$ (reproduced with permission). 


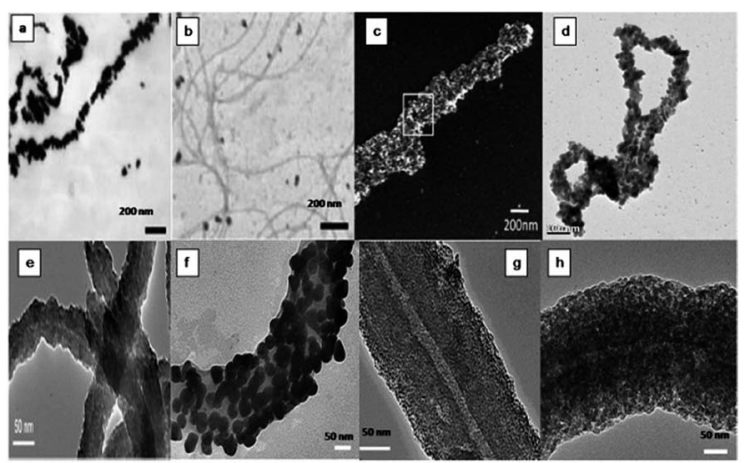

Fig. 6 Microscopic images of materials prepared using bacterial flagella as biotemplate. TEM images of $\mathrm{Pd}\left({ }^{\prime \prime}\right)$ (a) and $\mathrm{Au}(\mathrm{III})$ treated flagella (b). ${ }^{33}$ SEM micrographs of annealed $\mathrm{TiO}_{2}$ thin film covered flagella filament (c). ${ }^{34}$ Polymerised flagella with silver nanoparticle impregnation (d). ${ }^{35}$ TEM micrographs of silica-mineralized flagella nanotubes (SMFNs) (e), gold NPs-metallized SMFNs (f), Palladium NPsmetallized SMFNs $(\mathrm{g})$, iron oxide NPs-metallized SMFNs $(h)^{41}$ (all images reproduced with permission).

bacterial flagella as template. ${ }^{43}$ Various materials synthesized using bacterial flagella are presented in Fig. 6 .

2.1.3 Bacterial pili. Recently, bacterial pili have also been studied as a biotemplate for preparing bionanomaterials of various morphologies. Pili from various bacteria like Geobacter sulfurreducens and Geobacter metallireducens behave as conductive protein filaments, which are produced under physiologically relevant conditions. Because of their metal like conductive nature, these pili are often called 'microbial nanowires'. They are responsible for electronic interaction between bacteria with inorganic electron acceptors and also for inter species electron exchange. Such conductive pili nanowires can be used in the field of microbial electrode synthesis and bioelectronics. ${ }^{44}$ Many types of nanostructures have been reported using pili as biotemplate. Zhu et al. ${ }^{45}$ reported the atomic layer deposition of various oxides like $\mathrm{Al}_{2} \mathrm{O}_{3}, \mathrm{TiO}_{2}$ and $\mathrm{ZnO}$ onto bacterial pili isolated from E.coli. Using this technique, they obtained 20-25 nm Al $\mathrm{O}_{3}$ coating onto the pili surface, which appeared like a nanofiber. These oxide coated pili based nanofiber may be used for functional nanoelectronic materials. Cao et $a l .{ }^{46}$ synthesized multichannel, nanorhombuses, and nanoflowers like silica pili hybrid nano-architectures using pili bundles, double layer lattices and multilayer lattices of pili, respectively, using tetraethyl ortho silicate (TEOS).

\subsection{Fungal biotemplate}

Fungi are eukaryotic microorganisms, which include yeasts and molds. These organisms are mostly filamentous in nature with few exceptions (like yeast). Owing to the greater metal bioaccumulation and tolerance, fungi have been considered as a potential candidate for biotemplates. ${ }^{47}$ Fungi and yeasts have the ability to produce metal nanoparticles/meso and nanostructure by intracellular or extracellular reducing enzymes and by biomimetic mineralization processes. ${ }^{4,48}$ Fungal hyphae have been used as a biotemplate for the synthesis of these structures. Fungal microwires were prepared from Aspergillus nidulans,
Aspergillus niger and Neurospora crassa exploiting the selfassembly property of gold ions onto the surface of fungal hypae. Monosodium glutamate was used as an external reducing agent for the synthesis and growth of gold nanoparticles onto the surface of fungal hyphae. The gold nanoparticle coated fungal hyphae grew along with fungal hyphae. Furthermore, these gold microwires were converted into free standing gold microtubules after subjecting them to super critical carbon-di-oxide extraction process. ${ }^{49}$ Bigall et al. ${ }^{50}$ developed three dimensional macroscopic and microscopic structures from a hybrid fungus-platinum structure by dehydrating the organic part using a critical point dryer. It was observed that such structures had the property to catalyse redox reactions and possessed optical properties similar to that of nanoparticles. Similar to Sugunan et al., ${ }^{49}$ Rehman et al. ${ }^{51}$ prepared a wire like structure by coating gold nanoparticles onto Aspergillus niger hypae. The growth of gold nanoparticle coated hyphal wire was achieved by growing the fungus in a nutrient medium. However heat treatment was used instead of a carbon di-oxide extraction process for extracting the fungal organic template to produce the porous wire like structure. Gold nanowires were prepared by allowing the self-organization of colloidal gold nanoparticles onto Aspergillus niger hyphae using positive phototropic fungal response. The increase in hyphal growth through visible light stimulation was exploited to achieve unidirectional growth of gold nanowires. ${ }^{52}$ Sharma and Srivastava $^{53}$ fabricated gold microwires using self organized amino acid functionalized gold nanoparticles on fungal mycelium of Rhizopus oryzae, Penicillium funiculosum, and Aspergillus parasiticus. These gold micronanowires were tested for their potential application in biosensors as functional electrodes. The gold microwires were found to have good electrochemical response, high stability, sensitivity and biocompatibility that can be potentially applied in the field of biosensors and catalysis. Yu et al. ${ }^{54}$ synthesized lithium manganese oxide microtubes using Mn oxidizing fungus Paraconiothyrium sp. $W L-2$ as a biotemplate and bio-oxidiser. These microtubes were found to have a varying level of lithium adsorption when calcined at different temperatures ranging from 300 to $700{ }^{\circ} \mathrm{C}$. Other than metal based nano/micro structures, scientist have also reported the synthesis of organic nanoparticles with potential applications in medicine. A novel naturally synthesized organic nanoparticle made of glycosaminoglycan and protein has been isolated from Arthrobotrys oligospora fungus. These organic nanoparticles were of 360 to $370 \mathrm{~nm}$ in size and had immune stimulatory and antitumor activity that can be used for immunochemotherapy. ${ }^{55}$ Similar to fungal mycelium; several researchers have considered yeast cells as a potential biotemplate for micro and nanostructure synthesis. Bio-templated hierarchical anatase phase $\mathrm{TiO}_{2}$ mesoporus structure with ordered pores was prepared using yeast cells via a biomimetic mineralization process. These highly porous $\mathrm{TiO}_{2}$ mesoporous structure showed high electrocatalytic activity and excellent oxygen reduction reaction efficiency ${ }^{56}$ Tian et al. ${ }^{57}$ synthesized a yeast templated zirconium phosphate mesoporous structure having a high electrocatalytic property for the oxygen reduction reaction (Fig. 7). These mesoporous zirconium phosphate 

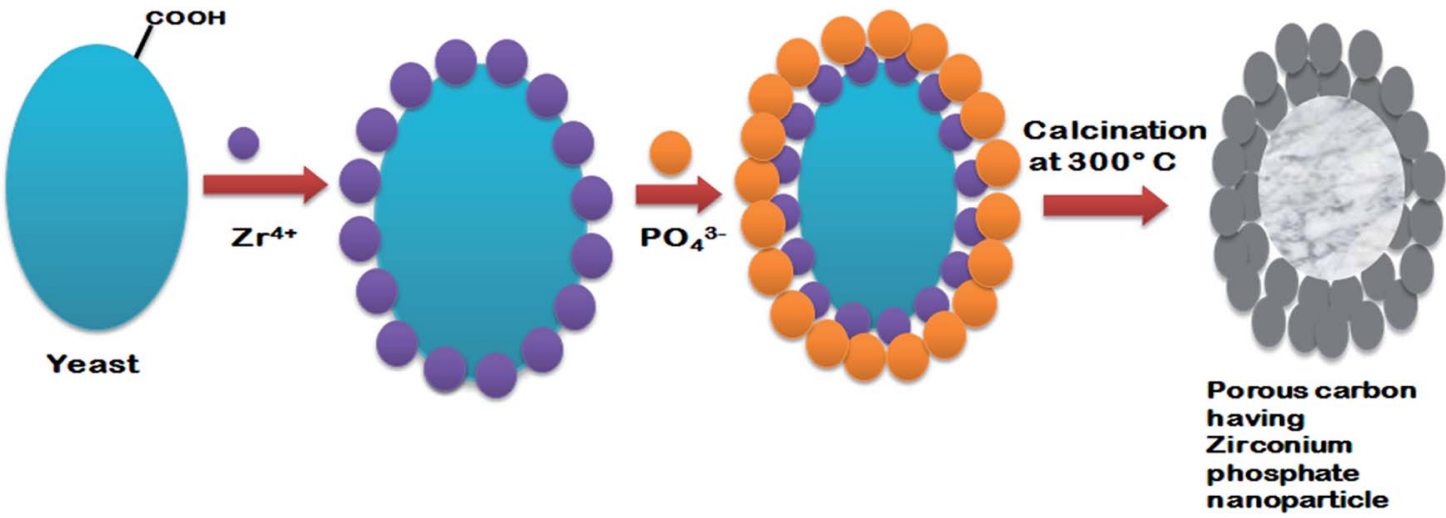

Fig. 7 Synthesis of porous carbon containing ordered hierarchical zirconium phosphate nanoparticles using yeast as a biotemplate. Adopted from ref. 57 with permission.

structures showed a better electrocatalytic property when compared to a commercially available manganese dioxide air electrode, and hence, it can be widely used in fuel cell technology. Wang et al. ${ }^{58}$ exploited Pastoris (PPCs) cells as a biotemplate to prepare closely packed, size controllable gold nanohorns (AuNHs) and AuNHs/PPCs nanocomposite by a chemical method. These AuNHs/PPCs nanocomposite exhibited high Raman enhancement effect when tested with Rhodamine $6 \mathrm{G}$.

\subsection{Algal biotemplates}

Algae are aquatic organisms with photosynthetic ability. They appear as either single cellular or multicellular organisms.
Similar to bacteria, the different morphological forms of algae, such as unicellular, filamentous and as colonies, can be used as a biotemplate for the synthesis of nanostructures. Various structured and patterned skeletal morphologies of algae that can be used for the biomimetic fabrication of nanostructures are presented in Fig. 8.

Some algae, like diatoms, take part in the process of mineralization, which is more fascinating to form different nanostructures. Diatoms are unicellular, eukaryotic microalgae that can be seen in fresh and saltwater ecosystems. Diatoms have a very interesting model system with high potential in the nano-structured production as there are almost 100000 different species with unique frustule morphologies. ${ }^{59}$ Diatoms

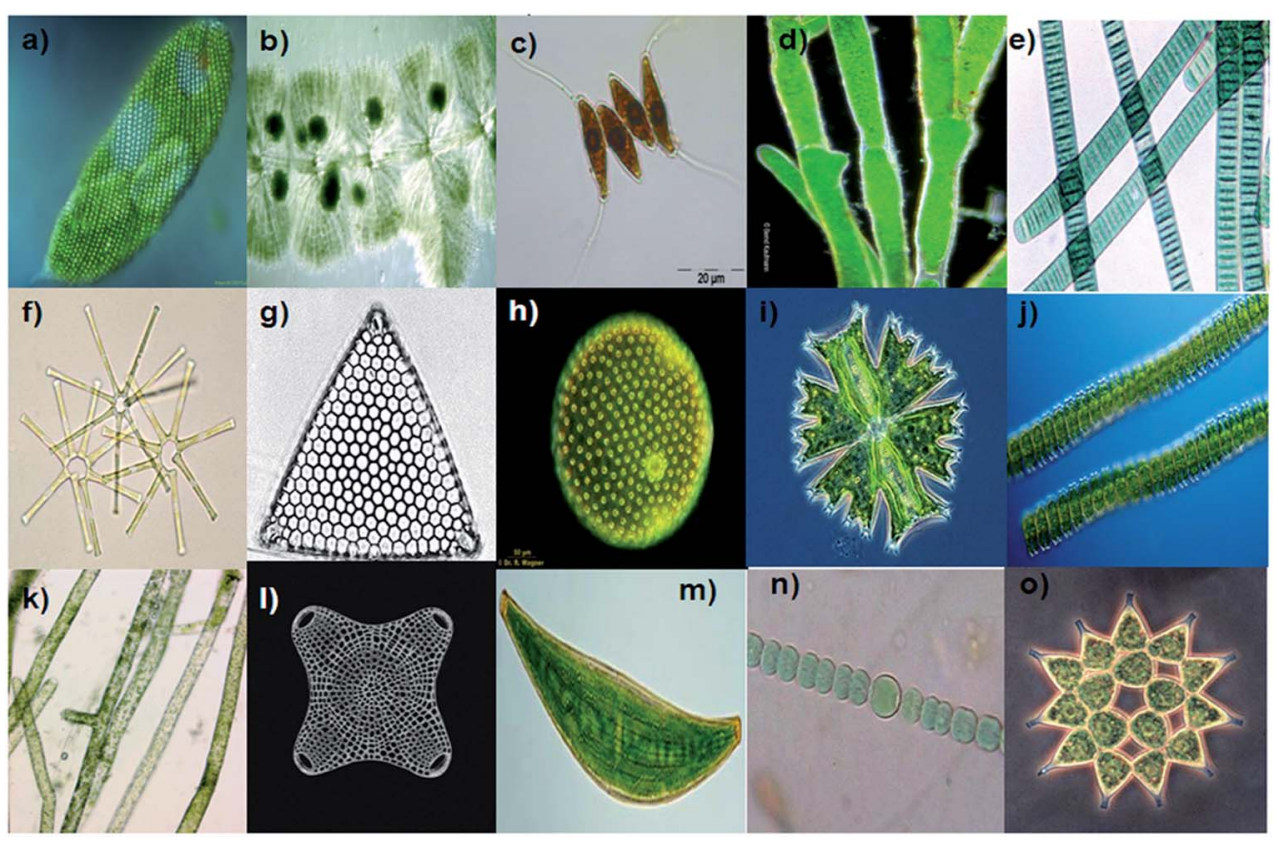

Fig. 8 Various structural and patterned skeletal morphology of algae that can be used for the biomimetic fabrication of nano/microstructures. Euglena spirogyra (a) Batrachospermum sp. (b) Desmodes musopoliensis (c) Pithophora sp. (d) (with multiseriate morphology), Oscillatoria sp. (e) Asterionella sp. (f) Triceratium favus (g) Volvox sp. (h) Micrasterias crux-melitensis (i) Desmidium swartzii (j) Vaucheria sp. (k) Biddulphia antediluvian (l) Closterium costatum (m) Anabaena sp. (n) Pediastrum sp. (o) (courtesy: Google images on algae and diatoms, http:// microscopy.uk.org) (ref. 86). 
have rigid cell wall structure called frustules, which are made of silica. These structures are created naturally in a controlled manner which provides them a unique morphology. These frustules have two halves called thecae. The top and bottom part of these thecae are called valves which are made of nanostructures granular silica. ${ }^{\mathbf{6 0 , 6 1}}$ The new theca are created in a vesicle called a silica deposition vesicle, which have silaffins and long-chain polyamines that are involved in the precipitation of silicic acid into silica. These silica shells are synthesized by the polymerization of silicic acid. This individual silica frustule consists of two valves, which are held together by bands like structures called girdle bands. There are three types frustules based on its structure viz., rod, flake and three dimensional (3D) shaped frustules. Rod shaped frustules show a higher assembling property with larger area coverage when compared to other shapes, which can be used in monolayer formation. Flake shaped frustules act as possible biocarriers and are used for biodetection. 3D frustules have very good porosity that can be used in drug delivery applications. ${ }^{62,63}$ The frustule valves are separated by plates, which appear like chambers. These plates contain pores varying in diameter either increasing or decreasing from outside to inside. The size and positioning of these pores are genetically determined. The smallest pore (40 $\mathrm{nm}$ ) has been observed in Coscinodiscus sp. and Thalassiosira eccentrica. ${ }^{\mathbf{6 4 , 6 5}}$ These unique structure and its skeletons have been considered as a potential biotemplate for the synthesis of various nanostructures that cannot be easily prepared by conventional and advanced techniques that are available. Although the silica structures in diatoms are brittle in nature, its nanoporous structure provides good toughness to the frustules, which can withstand considerable environmental stress. The brittle nature of these frustules can be changed into ductile through structural arrangements at the nanoscale level. ${ }^{66} \mathrm{Al} / \mathrm{Tp}$ ordered macroporous-mesoporous carbonaceous materials were prepared using Thalassiosira pseudonana as a biotemplate. ${ }^{67}$ Zhou et al. ${ }^{68}$ synthesized ordered porous ZnS nanostructures using Coscinodiscus lineatus as a biotemplate via a sonochemical method (Fig. 9). Using such a biotemplate and biomineralisation process, various materials have been developed for multiple applications. A few of the recently reported diatom based materials are shown Table 1 . The nano and microstructures produced using diatoms as biotemplates are presented in Fig. 10.

\subsection{Viral templates}

Viruses are infectious agents composed of a proteinaceous shell surrounding their genetic material that can live only in living cells. They lack their innate metabolic activity and remains as virions (for more introductions on viruses, its classification and structure, the readers are advised to refer to basic microbiology books). This property makes viruses as suitable and safe building blocks for preparing composite materials. ${ }^{69}$ The protein shell of virions facilitates mineralization/metallization process via amino acids present on their surface. For example, aspartic acid, glutamic acid, lysine, arginine and cysteine amino acids present in a viral cell wall have more affinity towards metal ions because of the presence of carboxylate, amino and thiol groups. Such affinity of viruses and virus like particles towards metals and ions has found immense application as scaffolds and templates for nanostructure formation. The molecules of interest are liganded via a bioconjugation process. The possibilities of viral manipulation and engineering through

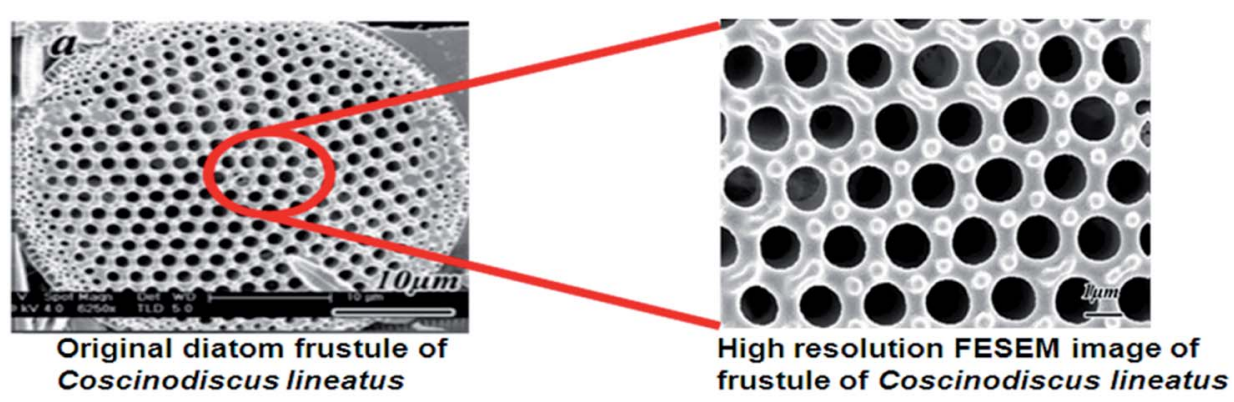

Sonochemical assembly of Zns nanoparticles

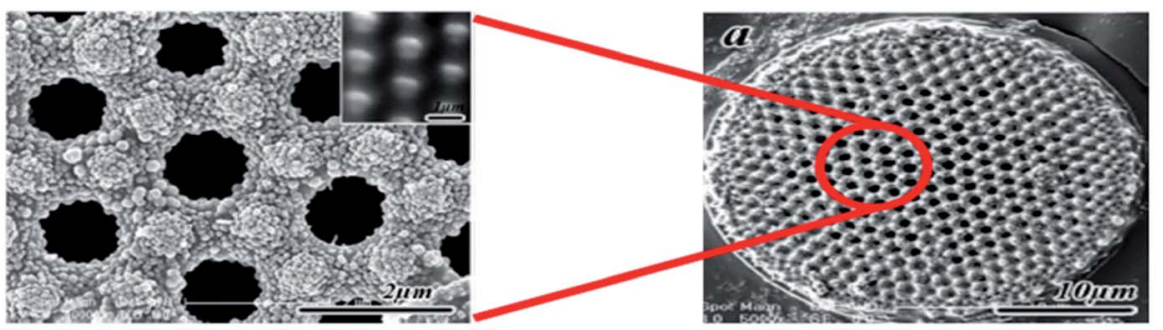

High resolution FESEM image of Whole silica-based $\mathrm{ZnS}$ replica of frustule of Coscinodiscus lineatus frustule of Coscinodiscus lineatus

Fig. 9 Synthesis of diatom-templated ordered porous ZnS meso/nanostructures ${ }^{68}$ (reproduced with permission). 


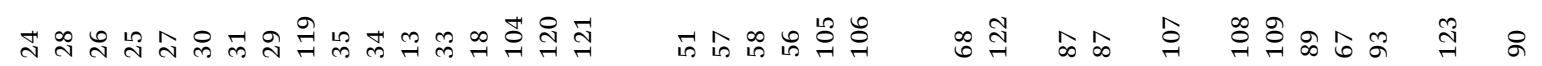
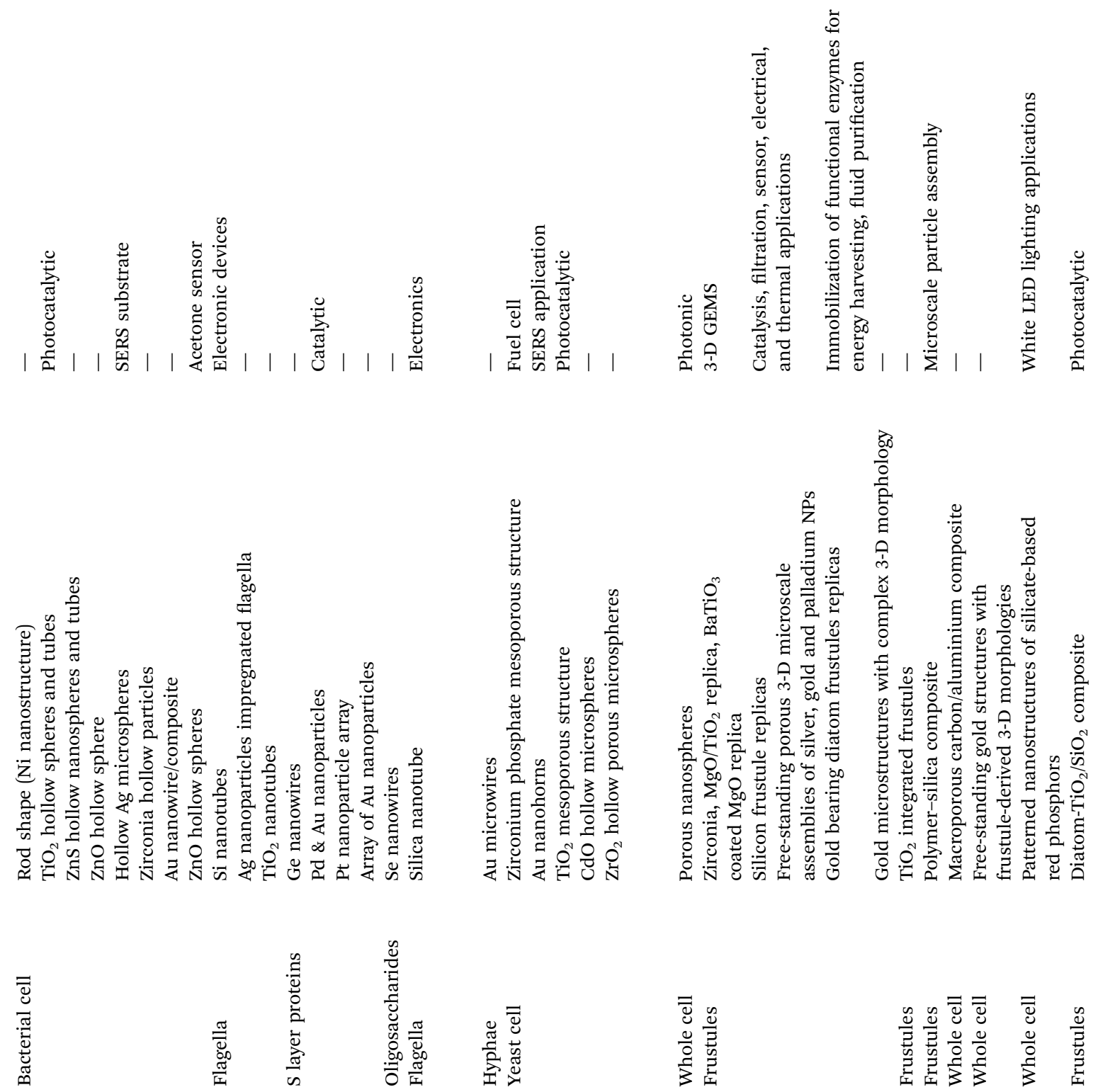

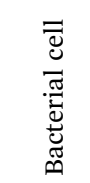
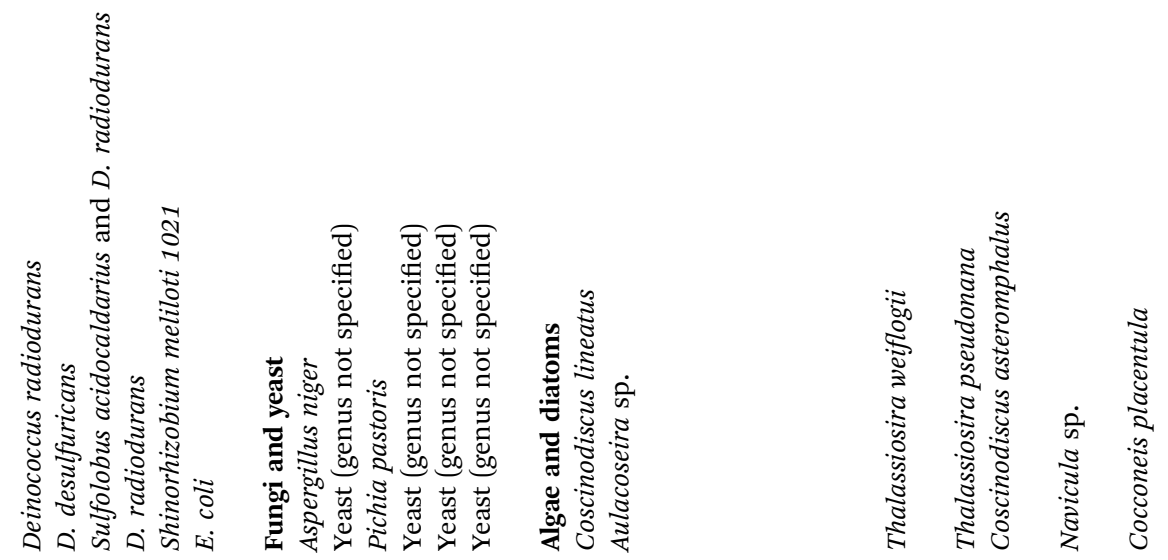

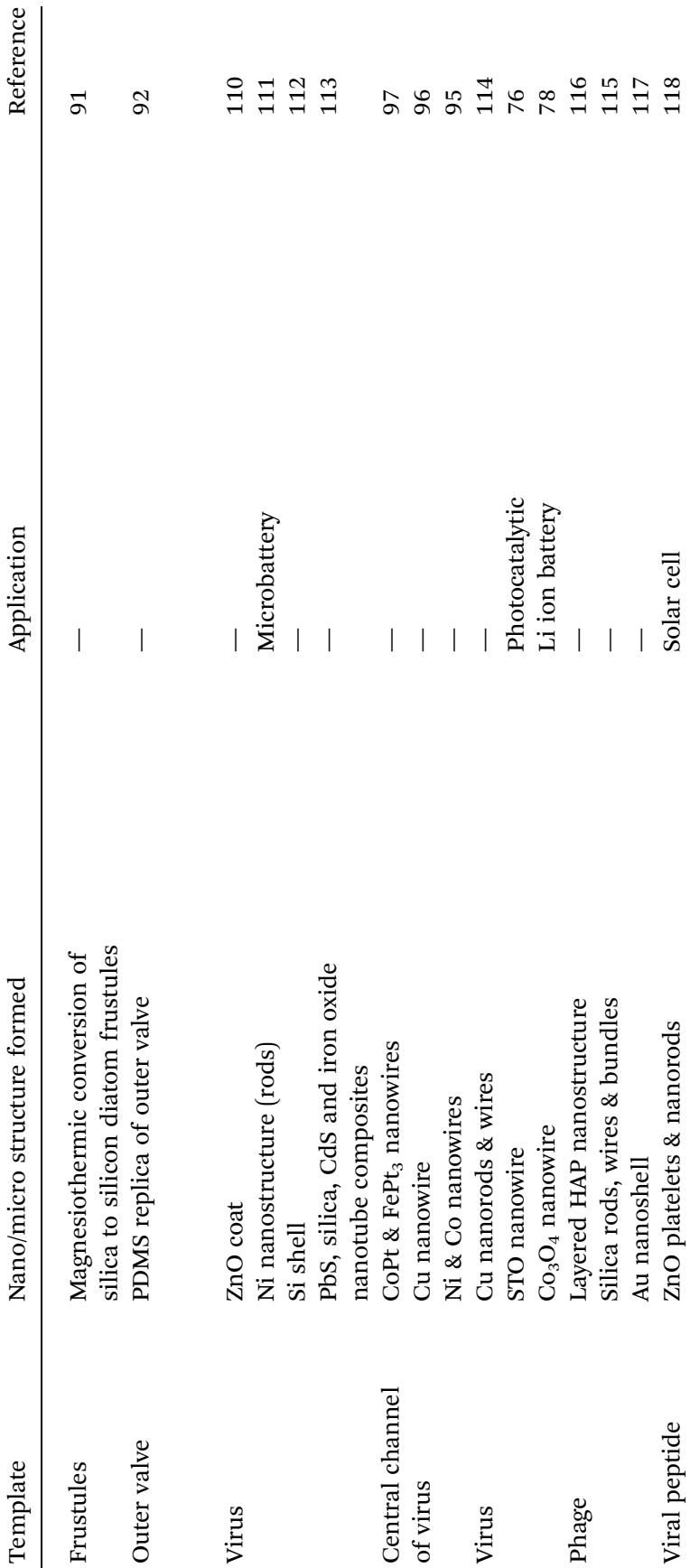

molecular biology techniques to impart specific display peptides have been a major boon for preparing customized nanomaterials through mineralization/metallization processes. ${ }^{69}$ The viral surfaces can also be chemically engineered to attain desirable properties. A few of the chemical and molecular biology approaches used to modify viral surfaces are bioconjugation and covalent modification, introduction of specific surface display genes through genetic engineering and membrane anchoring. These virus based materials can be two dimensionally arranged on a large scale by integrating with conventional patterning techniques such as microcontact printing, dip pen nanolithography, Langmuir-Blodgett lithography and molecular combing: ${ }^{\mathbf{7 0}^{-72}}$ Please refer to Fischlechner and Donath, ${ }^{69}$ for knowing more on the basics of using viruses as building blocks for preparing materials and devices. Most of the viruses used by scientists are plant viruses and are selected on the basis of their nonpathogenecity to human beings and animals. The frequently studied viruses for biotemplating are non enveloped plant viruses like tobacco mosaic virus (TMV), cowpea mosaic virus (CPMV), or cowpea chlorotic mottle virus (CCMV). They are also selected on the basis of the shape and size requirement. For example, viruses such as M13 phage and TMV are rod shaped and CCMV and CPMV are spherical shaped viruses. The length, inner and outer diameter of TMV are 300, 4 and $18 \mathrm{~nm}$, respectively. ${ }^{73}$ This inner diameter has a great significance in forming nanostructures. Various metal nanowires, nanorods and nanotubes have been made by exploiting the central channel and outer coat proteins of virus as both templates and metal binding sites (Fig. 11). Apart from these methods a few recent studies have also reported the synthesis of new nanomaterials using TMV for various applications (Fig. 12). Since, Love et al. ${ }^{74}$ and $\mathrm{Li}$ and Wang, ${ }^{75}$ have made a detailed review on TMV, we have excluded the details cited in these articles in order to avoid repetition. More focus is given to M13 viruses.

2.4.1 M13 viruses. M13 is a rod shaped filamentous virus having different types of outer coat proteins (pIII, pVI, pVII, pVIII and pIX), which can be genetically modified. The property of these outer coat proteins of M13 phages have been used in nanomaterial synthesis. Among these proteins, pVIII is a major coating protein that has been extensively studied. Nuraje et al. ${ }^{76}$ produced perovskite nanomaterials using genetically engineered M13 virus that expresses the pVIII coating protein. Strontium titanate and bismuth ferrite nanomaterials were prepared using genetically engineered viruses for therapeutics and imaging ${ }^{77}$ and nanowires for lithium ion battery electrodes. ${ }^{78}$ Ghosh et al. ${ }^{77}$ used M13 phages as a scaffold to carry more iron oxide nanoparticles and a SPARC-binding peptide ligand that can efficiently bind with cancer cell surfaces than an iron oxide nanoparticle carrier. Recently, Dong et al. ${ }^{79}$ obtained a high discharge capacity in lithium batteries using sulfur bound M13 phage particles as cathode. They have used the innate binding affinity of phage towards sulfur. It was found that the binding of sulfur occurs on the sides of $\mathrm{p} 8$ coat protein of the phage rather than the ends (p3). M13 phage was used to develop an electrode for battery applications. Manganese oxide was coated on the integrated phage particles; these composites 


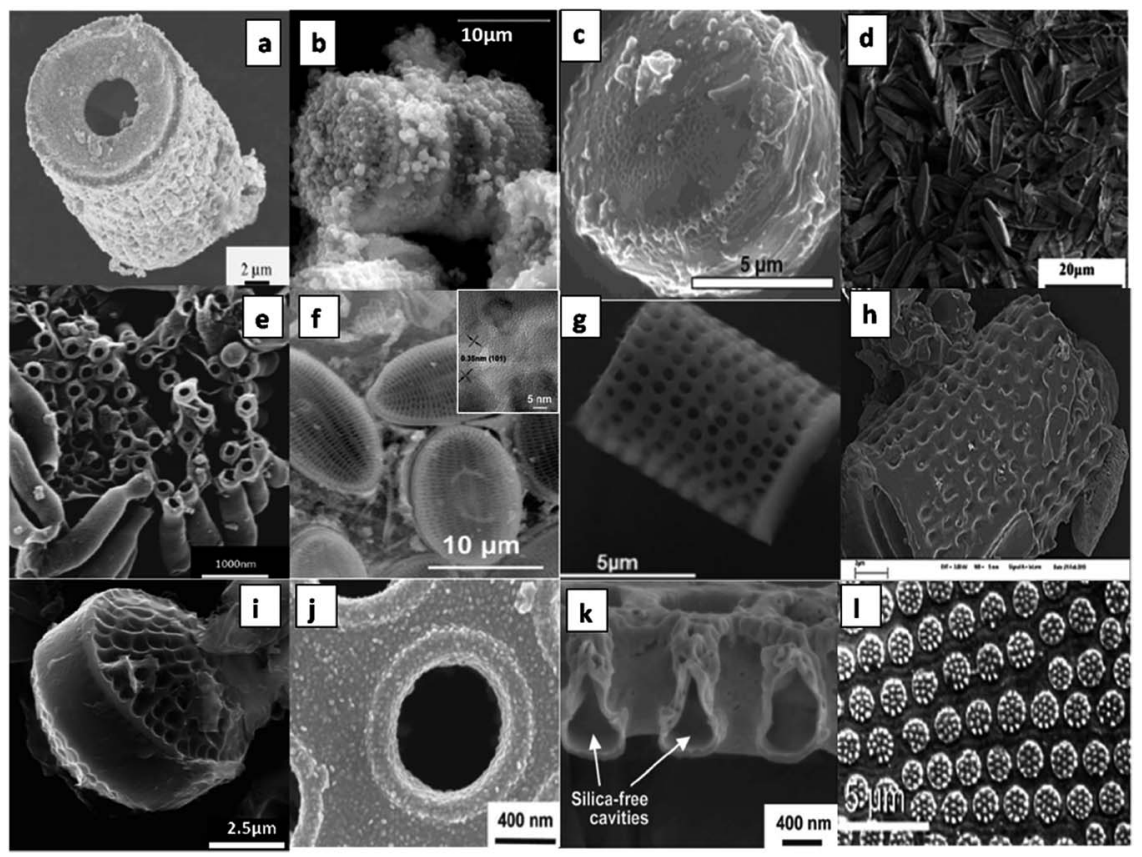

Fig. 10 Microscopic images of materials prepared using various diatom as biotemplate, Palladium frustule replica synthesized via electroless deposition (a), ${ }^{87}$ diatomite with faujastic crystals (b), ${ }^{88}$ polymer-silica composite made using T. weissflogii frustules (c), ${ }^{89} \mathrm{Navicula}$ frustules after annealing at $1000{ }^{\circ} \mathrm{C}$ for $2 \mathrm{~h} \mathrm{(d),}{ }^{123}$ macroporous carbon/aluminium composite obtained from Thalassiosira pseudonana (e), ${ }^{67}$ diatom- $\mathrm{TiO}_{2} / \mathrm{SiO}_{2}$ composite of Cocconeis placentula frustules (inset: high resolution image of $\mathrm{TiO}_{2} / \mathrm{SiO}_{2}$ ) (f), ${ }^{90} \mathrm{SEM}$ images of an Aulacoseira sp. frustule after the magnesiothermic conversion process (g), ${ }^{91}$ Carbon nitride coated onto single frustules of Celatom FW-14 diatomite (h), ${ }^{82}$ carbon/Al-Thalassiosira psesudonana (C/Al-Tp) composites (i) ${ }^{67}$ gold-coated Coscinodiscus asteromphalus frustule valve (j), ${ }^{93}$ free standing silica free cavities after ion milling gold coated Coscinodiscus asteromphalus (k), ${ }^{93}$ gold structures replicated from the frustules of Coscinodiscus species (l) ${ }^{94}$ (all images reproduced with permission)

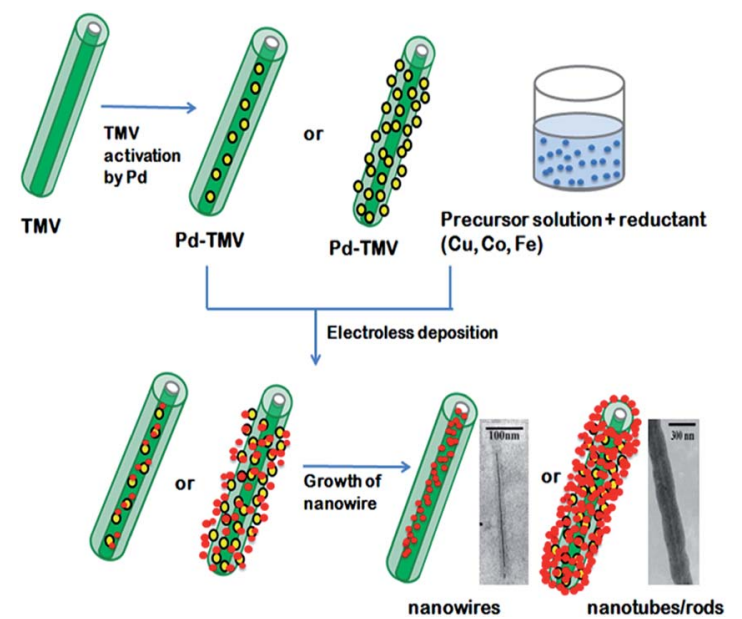

Fig. 11 Schematic diagram for the synthesis of nanowires and nanotubes/rods using inner channel and outer coat protein of TMV, respectively ${ }^{95-97,110}$ (all images reproduced with permission).

showed good discharge capacity upto 60 cycles. $^{80}$ M13 phage particles were modified or functionalized with a gold binding peptide to express on their surface. These functionalized phages showed the controlled mineralization of gold nanoparticles compared to non-modified M13 phages. The binding strength of gold nanoparticles depended on the expression of gold binding peptides on the phages. ${ }^{81}$ Liu et al. ${ }^{82}$ have worked on

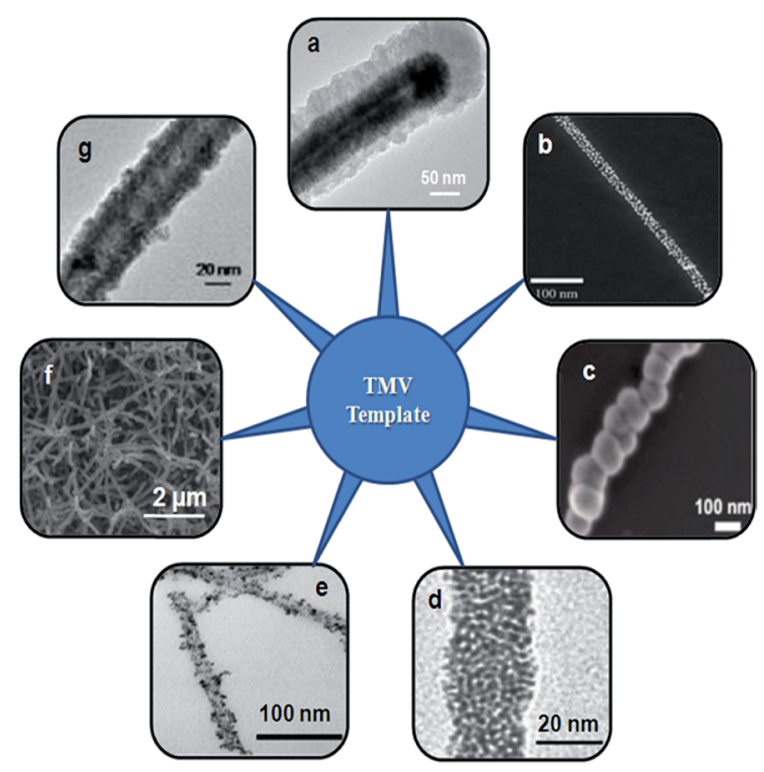

Fig. 12 Various nanostructures prepared using TMV as biotemplate. TEM image of a nonvertical TMV1cys/Ni/Si nanowires after 45 min of silicon PVD (a), ${ }^{98}$ SEM image of TMV rods decorated with citratecoated AuNPs (b), ${ }^{99}$ SEM micrograph of the growth of nickel on TMV during ELD (c), ${ }^{100}$ TEM image of Pt-TMV nanotube (d), ${ }^{101}$ TEM image of palladium-deposited TMV1Cys at $25{ }^{\circ} \mathrm{C}$ with different molar ratio of palladium-ion to TMV1Cys (e), ${ }^{102}$ SEM image TMV after tin electrodeposition (f), ${ }^{103}$ TEM Image of Cu-TMV (g). ${ }^{114}$ (Reproduced with permission). 
genetically modified M13 phages, which express positively charged peptides to form nanocomposite films. Films were formed by a layer by layer (LBL) assembly of positively charged peptides on M13 templates. Gold nanoparticles have also been assembled through LBL assembly and these biotemplated architectures were used for surface plasmon resonance based applications. Filamentous M13 phage mutated by site directed mutagenesis has been used as a photoresponsive organic nanowire. The virus was genetically engineered for tyrosine to react with an azo dye. Because of this chemical reaction, the M13 and azo complex showed a reversible photoresponsive property. This is one of the examples that organic M13 phage can be used for the chemical reaction through site directed mutagenesis. These modified viral nanowires have major applications in optics and data storage. ${ }^{83}$ Table 1 shows a consolidated review on nano/microstructures synthesized using bacteria, fungi, algae and viruses and their applications studied.

\section{Conclusion}

The need of nano/microstructures with different and defined size, shape and morphology for various applications in the field of electronics, environment, biotechnology and healthcare is always on the rise. Such diverse nanoparticle morphology is achievable using microorganisms as biotemplates. These microbial templates have several advantages, which can be potentially utilized to produce/synthesis nano/micron sized structures/particles of varying morphology that were not possible in recent advanced manufacturing/synthesis techniques like lithography. The major advantages of using microbes as biotemplates are easy mass production, defined shape, tunable size, metal binding capacity, reproducibility of results, possibility for surface functionalization and its a green and ecofriendly process. From this review, it is evident that several nano/microstructures prepared using microbial biotemplates has required properties that are needed for specific applications. Although this review indicates the possibility of using various microbes as biotemplates, the research is still in the early stage and yet to be realized at the product level. The microbial biotemplates in the future may be applicable to new concepts like non toxic, high conductivity organic based electronic materials like transistors and supercapacitors. Hence, these nanomaterials derived from microbial template may be studied for their effect on real time applications for sustained use in product manufacturing.

\section{Acknowledgements}

The authors of this paper acknowledge the help rendered by other authors who have responded by sending their full text. Dr R. Selvakumar acknowledges the help rendered by Centre for Environmental Risk Assessment and Remediation (CERAR), University of South Australia, Australia and PSG Institute of Advanced Studies, Coimbatore, India, for supporting this review work.

\section{References}

1 S. Sotiropoulou, Y. Sierra-Sastre, S. S. Mark and C. A. Batt, Chem. Mater., 2008, 20, 821.

2 S. Dougherty, Template-assisted fabrication of nanobiomaterials, Ph.D thesis, Worcester polytechnic institute, 2009.

3 C. R. Lowe, Curr. Opin. Struct. Biol., 2000, 10, 428.

4 T. Fan, S. Chow and D. Zhang, Prog. Mater. Sci., 2009, 54, 542.

5 W. J. Landis, Bone, 1995, 16, 533.

6 R. Kane and P. X. Ma, Mater. Today, 2013, 16, 418.

7 A. Mukherjee, Biomimetics learning from nature, Intech Publishing, 2010.

8 J. Huang, X. Wang and Z. L. Wang, Nano Lett., 2006, 6, 2325. 9 V. Sarananthan, C. O. Osuji, S. G. J. Mochrie, H. Noh, S. Narayanan, A. Sandy, E. R. Dufresne and R. O. Prum, PNAS, 2010, 107, 11676.

10 R. Selvakumar, K. K. Karthikeyan and P. Radhakrishnan, Micron, 2012, 43, 1299.

11 R. Selvakumar, N. Arul Jothi, V. Jayavignesh, K. Karthikaiselvi, G. I. Antony, P. R. Sharmila, S. Kavitha and K. Swaminathan, Water Res., 2011, 45, 583.

12 R. Selvakumar, S. Aravind, M. A. Anuradha and Y. L. Balachandran, J. Exp. Nanosci., 2014, 9, 1075-1087.

13 Y. Sierr-Sastre, S. A. Dayeh, S. T. Picraux and C. A. Batt, ACS Nano, 2010, 4, 1209.

14 U. B. Sleytr, FEMS Microbiol. Rev., 1997, 20, 5.

15 U. B. Sleytr, M. Sara, D. Pum, B. Schuster, P. Messner and C. Schaffer, in Biopolymers: Polyamides and Complex Proteinaceous Matrices I, ed. A. Steinbuchel and S. R. Fahnestock, Wiley-VCH, Weilheim, 2002.

16 U. B. Sleytr and P. Messner, Encycl. Microbiol., 2009, 1, 89.

17 D. Pum, J. L. Toca-Herra and U. B. Sleytr, Int. J. Mol. Sci., 2013, 14, 2484.

18 S. S. Mark, M. Bergkvist, X. Yang, L. M. Teixeira, P. Bhatnagar, E. R. Angert and C. A. Batt, Langmuir, 2006b, 22, 3763.

19 S. S. Mark, M. Bergkvist, X. Yang, E. R. Angert and C. A. Batt, Biomacromolecules, 2006a, 7, 1884.

20 S. S. Mark, M. Bergkvist, P. Bhatnagar, C. Welch, A. L. Goodyear, X. Yang, E. R. Angert and C. A. Batt, Colloids Surf., B, 2007, 57, 161.

21 D. Schuster, S. Küpcüa, D. J. Belton, C. C. Perry, M. StögerPollach, U. B. Sleytr and D. Puma, Acta Biomater., 2013, 9, 5689.

22 J. Lee, M. Kim, B. Yoo, N. V. Myung, T. Lee, A. C. Dohnalkova, J. K. Fredrickson, M. J. Sadowsky and H. Hur, PNAS, 2007, 104, 20410.

23 K. B. Narayanan and N. Sakthivel, Adv. Colloid Interface Sci., 2010, 156, 1.

24 K. Ashtari, J. Fasihi, N. Mollania and K. Khajeh, Mater. Res. Bull., 2014, 50, 348.

25 H. Zhou, T. Fan and D. Zhang, Microporous Mesoporous Mater., 2007a, 100, 322. 
26 H. Zhou, T. Fan, D. Zhang, Q. Cuo and H. Ogawa, Chem. Mater., 2007b, 19, 2144.

27 D. Yang, S. Chen, P. Huang, X. Wang, W. Jiang, O. Pandoli and D. Cui, Green Chem., 2010, 12, 2038.

28 H. Zhou, T. Fan, J. Ding, D. Zhang and Q. Guo, Opt. Express, 2012, 20, 340.

29 H. Zhang, C. Xu, P. Sheng, Y. Chen, L. Yu and Q. Li, Sens. Actuators, B, 2013, 81, 99.

30 T. Nomura, S. Tanii, M. Ishikawa, H. Tokumoto and Y. Konishi, Adv. Powder Technol., 2013, 24, 1013.

31 H. Yang, M. Du, T. Odoom-Wubah, J. Wang, D. Sun, J. Huang and Q. Li, J.Chem. Technol. Biotechnol., 2014, 89, 1410-1418.

32 B. Kaehr and C. J. Brinker, Chem. Commun., 2010, 46, 5268.

33 K. Deplanche, R. D. Woods, I. P. Mikheenko, R. E. Sockett and L. E. Macaskie, Biotechnol. Bioeng., 2008, 101, 873.

34 W. R. Hesse, L. Luo, G. Zhang, R. Mulero, J. Cho and M. Kim, Mater. Sci. Eng., C, 2009, 29, 2282.

35 P. Gopinathan, M. A. Anuradha and R. Selvakumar, Appl. Surf. Sci., 2013, 276, 717.

36 P. Gopinathan, Impact of silver nanoparticle decorated flagellar bionanocomposites on electrode performance in microbial fuel cells used for dye degradation, M. Phil. thesis, Bharathiar University, 2012.

37 T. K. Mudalige, N. Srividya, M. Subra and C. T. Briyan, Nano Lett., 2006, 6, 2121.

38 T. K. Mudalige, M. Subra and C. T. Briyan, J. Nanosci. Nanotechnol., 2007, 7, 2260.

39 H. H. Salman, J. M. Irache and C. Gamazo, Vaccine, 2009, 27, 4784.

40 F. Wang, D. Li and C. Mao, Adv. Funct. Mater., 2008, 18, 4007.

41 W. Jo, K. J. Freedman and M. J. Kim, Mater. Sci. Eng., C, 2012, 32, 2426.

42 D. Li, X. Qu, S. M. C. Newton, P. E. Klebba and C. Mao, J. Mater. Chem., 2012a, 22, 15702.

43 D. Li, B. Mathew and C. Mao, Small, 2012b, 8, 3691.

44 N. S. Malvankar and D. R. Lovely, ChemSusChem, 2012, 5, 1039.

45 Y. Zhu, B. Cao, R. Nicholas, C. Mao and M. Kane, J. Electrochem. Soc., 2010, 1449.

46 B. Cao, H. Xu and C. Mao, Angew. Chem., 2011, 123, 6388.

47 M. Sastry, A. Ahmad, M. I. Khan and R. Kumar, Curr. Sci., 2003, 85, 162.

48 K. Quester, M. Avalos-Borja and E. Castro-Longoria, Micron, 2013, 54-55, 1.

49 A. Sugunan, P. Melin, J. Schnurer, J. G. Hilborn and J. Dutta, Adv. Mater., 2007, 19, 77.

50 N. C. Bigall, M. Reitzig, W. Naumann, P. Simon, K. V. Pee and A. Eychmuller, Angew. Chem., 2008, 47, 7876.

51 A. Rehman, M. I. Majeed, A. Ihsan, S. Z. Hussain, S. urRehman, M. A. Ghauri, Z. M. Khalid and I. Hussain, J. Nanopart. Res., 2011, 13, 6747.

52 A. Sabah, P. Kumar, W. S. Mohammed and J. Dutta, Part. Part. Syst. Charact., 2013, 30, 473.

53 S. Sharma and S. Srivastava, Biosens. Bioelectron., 2013, 50, 174.
54 Q. Yu, K. Sasaki and T. Hirajima, J. Hazard. Mater., 2013, 262, 38.

55 Y. Wang, L. Sun, S. Yi, Y. Huang, S. C. Lenaghan and M. Zhang, Adv. Funct. Mater., 2012, 23, 2175.

56 J. Cui, W. He, H. Liu, S. Liao and Y. Yue, Colloids Surf., B, 2009, 74, 274.

57 X. Tian, W. He, J. Cui, X. Zhang, W. Zhou, S. Yan, X. Sun, X. Han, S. Y. Han and S. Yue, J. Colloid Interface Sci., 2010, 343, 344.

58 M. Wang, T. Odoom-Wubah, H. Chen, X. Jing, T. Kong, D. Sun, J. Huang and Q. Li, Nanoscale, 2013, 5, 6599.

59 L. Zyga, Microorganisms act as tiny machines in future MEMS devices, 2007, http://PHYSorg.com.

60 M. J. Hildebrand, Nanosci. Nanotechnol., 2005, 5, 146.

61 W. J. Crookes-Goodson, J. M. Slocik and R. R. Naik, Chem. Soc. Rev., 2008, 37, 2403.

62 Z. D. Yuan, W. Yu, C. Jun, P. J. Feng, J. X. Gang and J. Y. Gang, Mech Eng, 2012, 57, 3836.

63 M. S. Aw, M. Bariana, Y. Yu, J. Addai-Mensah and D. Losic, J. Biomater. Appl., 2012, 28, 163.

64 D. Losic, J. G. Mitchell and N. H. Voelcker, Adv. Mater., 2009, 21, 2947.

65 D. Losic, R. J. Pillar, T. Dilger, J. G. Mitchell and N. H. Voelcker, J. Porous Mater., 2007, 14, 61.

66 A. P. Garcia, D. Sen and M. J. Buelhler, Metall. Mater. Trans. A, 2011, 42, 3889.

67 M. Perez-Cabero, V. Puchol, D. Beltran and P. Amoros, Carbon, 2008, 48, 297.

68 H. Zhou, T. Fan, X. Li, J. Ding, D. Zhang, X. Li and Y. Gao, Eur. J. Inorg. Chem., 2009, 2009, 211.

69 M. Fischlechner and E. Donath, Angew. Chem., 2007, 46, 3184.

70 A. P. Quist, E. Pavlovic and S. Oscarsson, Anal. Bioanal. Chem., 2005, 381, 591.

71 R. A. Vega, D. Maspoch, K. Salaita and C. A. Mirkin, Angew. Chem., Int. Ed., 2005, 44, 6013.

72 J. Guan and L. J. Lee, PNAS, 2005, 102, 18321.

73 C. M. Soto and B. R. Ratna, Curr. Opin. Biotechnol., 2010, 21, 426.

74 A. J. Love, V. Makarov, I. Yaminsky, N. O. Kalinina and M. E. Taliansky, Virology, 2014, 449, 133.

75 F. Li and Q. Wang, Small, 2014, 10, 230.

76 N. Nuraje, X. Dang, J. Qi, M. A. Allen, Y. Lei and A. M. Belcher, Adv. Mater., 2012, 24, 2885.

77 D. Ghosh, Y. Lee, S. Thomas, A. G. Kohli, D. S. Yun, A. M. Belcher and K. A. Kelly, Nat. Nanotechnol., 2012, 7, 677.

78 K. T. Nam, D. Kim, P. L. Yoo, C. Chiang, N. Meethong, P. T. Hammond, Y. Chiang and A. M. Belcher, Science, 2006, 312, 885.

79 D. Dong, Y. Zhang, S. Sutaria, A. Konarov and P. Chen, PLoS One, 2013, 8, 82332.

$80 \mathrm{~J}$. Hwangbo, Fabrication of nanostructured manganese oxide electrode with M13 phage template, thesis: Master of Applied Science, University of Waterloo, Canada, 2013.

81 D. Rothenstein, S. J. Facy, M. Ploss, P. Hans, M. Melcher, V. Srot, P. A. Aken, B. Hauer and J. Bill, Bioinspired, Biomimetic Nanobiomater., 2013, 2, 173. 
82 J. Liu and M. Antonietti, Energy Environ. Sci., 2013, 6, 1486. 83 M. Murugesan, G. Abbineni, S. L. Nimmo, B. Cao and C. Mao, Sci. Rep., 2013, 3, 1820.

84 T. Nomura, Y. Morimoto, M. Ishikawa, H. Tokumoto and Y. Konishi, Adv. Powder Technol., 2010, 21, 8.

85 H. Shim, A. Lim, J. Kim, E. Jang, S. Seo, G. Lee, T. D. Kim and D. Kim, Sci. Rep., 2013, 3, 1.

86 Google images on algae and diatoms, http:// microscopy.uk.org.

87 Z. Bao, E. M. Ernst, S. Yoo and K. H. Sandhage, Adv. Mater., 2009, 21, 474.

88 H. Oscar, I. H. Patrick, D. J. Doocey and S. M. Holmes, J. Mater. Chem., 2007, 17, 1804.

89 J. O'Connor, Y. Lang, J. Chao, H. Cao, L. Collins, B. J. Rodriguez, P. Dockery, D. P. Finn, W. Wang and A. Pandit, Small, 2013, 10, 469.

90 J. He, D. Chen, Y. Li, J. Shao, J. Xie, Y. Sun, Z. Yan and J. Wang, Appl. Phys. A, 2013, 113, 327.

91 S. Chandrasekaran, M. J. Sweetman, K. Kant, W. Skinner, D. Losic, T. Nann and N. H. Voelcker, Chem. Commun., 2014, 50, 10441.

92 M. R. Belegratis, V. Schmidt, D. Nees, B. Stadlober and P. Hartmann, Bioinspiration Biomimetics, 2014, 9, 016004.

93 Y. Fang, V. W. Chen, Y. Cai, J. D. Berrigan, S. R. Marder, J. W. Perry and K. H. Sandhage, Adv. Funct. Mater., 2012, 22, 2550.

94 D. Losic, J. G. Mitchell and N. H. Voelcker, Chem. Commun., 2005, 4905.

95 M. Knez, A. M. Bittner, F. Boes, C. Wege, H. Jeske, E. Mai and K. Kern, Nano Lett., 2003, 3, 1079.

96 S. Balci, A. M. Bittner, K. Hahn, C. Scheu, M. Knez, A. Kadri, C. Wege, H. Jeske and K. Kern, Electrochim. Acta, 2006, 51, 6251.

97 R. Tsukamoto, M. Muraoka, M. Seki, V. Tabata and I. Yamashita, Chem. Mater., 2007, 19, 2389.

98 X. Chen, K. Gerasopoulos, J. Guo, A. Brown, C. Wang, R. Ghodssi and J. N. Culver, ACS Nano, 2010, 7, DOI: 10.1021/nn100963j.

99 A. A. Khan, E. K. Fox, M. L. Gorzny, E. Nikulina, D. F. Brougham, C. Wege and A. M. Bittner, Langmuir, 2013, 29, 2094.

100 Z. Wu, R. Zierold, A. Mueller, S. E. Ruff, C. Ma, A. A. Khan, F. Geiger, B. A. Sommer, M. Knez, K. Nielsch, A. M. Bittner, C. Wege and C. E. Krill, Phys. Status Solidi B, 2010, 247, 2412.

101 M. L. Gorzny, A. S. Walton and S. D. Evans, Adv. Funct. Mater., 2010, 20, 1.
102 J. Lim, S. Kim, S. Lee, E. A. Stach, J. N. Culver and M. H. Harris, J. Colloid Interface Sci., 2010, 342, 455.

103 X. Chen, J. Guo, K. Gerasopoulos, A. Langrock, A. Brown, R. Ghodssi, J. N. Culver and C. Wang, J. Power Sources, 2012, 211, 129.

104 M. Bergkvist, S. S. Mark, X. Yang, E. R. Angert and C. A. Batt, J. Phys. Chem. B, 2004, 108, 8241.

105 B. Bai, W. Guan, Z. Li and G. L. Puma, Mater. Res. Bull., 2011, 46, 26.

106 X. Fan, X. Song, X. Yang and L. Hou, Mater. Res. Bull., 2011, 46, 1315.

107 S. C. Davis, V. C. Sheppard, G. Begum, Y. Cai, Y. Fang, J. D. Berrigan, N. Kröger and K. H. Sandhage, Adv. Funct. Mater., 2013, 23, 4611.

108 Y. Yu, J. Addai-Mensah and D. Losic, Langmuir, 2010, 26, 14068.

109 Y. Lang, F. Monte, B. J. Rodriguez, D. P. Finn and A. Pandit, Sci. Rep., 2013, 3, 3205.

110 S. Balci, A. M. Bittner, M. Schirra, K. Thonke, R. Sauer, K. Hahn, A. Kadri, C. Wege, H. Jeske and K. Kern, Electrochim. Acta, 2009, 54, 5149.

111 K. Gerasopoulos, M. McCarthy, E. Royston, J. N. Culver and R. Ghodssi, J. Micromech. Microeng., 2008, 18, 104003.

112 E. S. Royston, A. D. Brown, M. T. Harris and J. N. Culver, J. Colloid Interface Sci., 2009, 332, 402.

113 W. Shenton, T. Douglas, M. Young, G. Stubbs and S. Mann, Adv. Mater., 1999, 11, 253.

114 J. C. Zhou, C. M. Soto, M. Chen, M. A. Bruckman, M. H. Moore, E. Barry, B. R. Ratna, P. E. Pehrsson, B. R. Spies and T. S. Confer, J. Nanobiotechnol., 2012, 10, 1.

115 Z. Zhang and J. Buitenhuis, Small, 2007, 3, 424.

116 F. Wang, B. Cao and C. Mao, Chem. Mater., 2010, 22, 3630.

117 C. Radloff and A. V. Vaia, Nano Lett., 2005, 5, 1187.

118 M. M. Tomczak, M. K. Gupta, L. F. Drummy, S. M. Rozenzhak and R. R. Naik, Acta Biomater., 2008, 5, 876.

119 W. Jo, Biologically Inspired Flagella-Templated Silica Nanotubes, Ph.D thesis, Drexel University, US, 2013.

120 S. Lee, C. Kwon, B. Park and S. Jung, Carbohydr. Res., 2009, 344, 1230.

121 W. Jo, U. K. Cheang and M. J. Kim, Nano Convergence, 2014, 1,10 .

122 K. H. Sandhage, S. M. Allan, M. B. Dickerson, C. S. Gaddis, S. Shian, M. R. Weatherspoon, Y. Cai, G. Ahmad, M. S. Haluska and R. L. Snyder, Int. J. Appl. Ceram. Technol., 2005, 2, 317.

123 G. Zhang, W. Jiang, L. Wang, X. Liao, P. Liu, X. Deng and J. Li, Mater. Lett., 2013, 110, 253. 